\title{
Evaluation of Conversion Coatings Without Hexavalent Chromium for Aerospace and Defense Applications
}

\author{
Gregory Morose ${ }^{1, *}$ (D), David Pinsky² (D), Chandler Humphrey³ (D), Kent DeFranco ${ }^{3}$ (D)
}

\author{
1. University of Massachusetts Lowell rọ - Toxics Use Reduction Institute - Lowell/MA - United States of America \\ 2. Raytheon Technologies - Andover/MA Rór - United States of America \\ 3. Lockheed Martin Aeronautics Rớ - Fort Worth/TX - United States of America \\ *Correspondence author: gregory_morose@uml.edu
}

\begin{abstract}
Conversion coatings containing hexavalent chromium are currently used in aerospace and defense manufacturing on various aluminum alloys to provide corrosion protection and enhanced adhesion of subsequent coatings. However, hexavalent chromium is toxic to humans with negative health effects from acute and chronic exposure. Regulatory mandates have accelerated a global effort to replace hexavalent chromium-containing materials because of their toxicity. A consortium was established to evaluate safer conversion coating materials, including the chemical processing of the surfaces prior to applying the conversion coatings. Four conversion coatings without hexavalent chromium were compared against a hexavalent chromium-based conversion coating for the following tests: coating weight, electrical contact resistance, paint adhesion, bare and painted neutral salt fog corrosion tests, painted $\mathrm{SO}_{2}$ salt fog corrosion test, and painted outdoor beachfront corrosion test. The test results for the four conversion coatings without hexavalent chromium were encouraging since several candidates exceeded some of the specification requirements or consortium expectations. In particular, the Socosurf TCS/PACS conversion coating performed well in the coating weight, electrical contact resistance, paint adhesion, and corrosion tests. The results of this evaluation provide significant progress toward providing a replacement material for a traditionally hexavalent chromium material application on aluminum.
\end{abstract}

Keywords: Conversion coating; Hexavalent chromium; Corrosion test; Paint adhesion; Aluminum alloy.

\section{INTRODUCTION}

Aluminum alloys are widely used in the aerospace industry because of their low density and enhanced mechanical properties due to alloy constituents such as copper, zinc, and magnesium. However, the addition of these alloy constituents can generate a heterogeneous microstructure and elevate the susceptibility to corrosion on the alloy surface. Copper is involved in the formation of intermetallic coarse particles, which when exposed to aqueous solutions can generate pitting corrosion (Saillard et al. 2018).

Conversion coatings containing hexavalent chromium compounds are currently being used in aerospace and defense manufacturing with different types of aluminum alloy. The conversion coatings are used to improve the adhesion of the primer layers that historically have included hexavalent chromium as a corrosion inhibitor. Hexavalent chromium provides a key role in the inhibition of corrosion of aluminum alloys. This corrosion inhibition is provided since hexavalent chromium oxy-anionic

Received: Jul. 28, 2021 | Accepted: Jan. 07, 2022

Peer Review History: Single Blind Peer Review.

Section Editor: Melih Kushan

This is an open access article distributed under the terms of the Creative Commons license. 
species inhibit cathodic reactions of copper containing aluminum alloys by a rapid adsorption process, and hexavalent chromium compounds adsorb on aluminum oxides, and that makes the films less susceptible to adsorption of chloride (Kendig et al. 2001).

Hexavalent chromium is toxic to humans with health effects from acute and chronic exposure. Acute exposure to hexavalent chromium can cause several health effects including, but not limited to, respiratory irritation, nosebleeds, running nose, nasal ulcerations, asthma exacerbations, skin burns, and pneumonia (ATSDR 2012). The International Agency for Research on Cancer (IARC) classifies hexavalent chromium compounds as group 1 (carcinogenic to humans). Chronic exposure to hexavalent chromium is associated with lung cancer, nasal, and sinus cancers (IARC 2012). There is also evidence regarding cancer risks associated with ingesting hexavalent chromium compounds, and human and animal studies document links to other types of cancer, such as skin, oral, and intestinal (Costa and Klein 2006). Intermediate and chronic respiratory exposure to hexavalent chromium (i.e., more than 15 days) can cause: damage to the nasal mucous membrane, perforation of the nasal septum, decreased pulmonary function, and asthma (NIOSH 2013).

Regulatory mandates have accelerated a global effort to replace hexavalent chromium-containing materials because of their toxicity. In 2011, the Defense Federal Acquisition Regulation Supplement mandated that applicable U.S. Department of Defense contracts do not include specifications that result in a deliverable or required maintenance material containing more than $0.1 \%$ hexavalent chromium in any homogeneous material in which acceptable substitutes are available. It also prohibits the use or removal of hexavalent chromium-containing materials during subsequent phases of the deliverable, unless an exception or approval applies. Conversion coatings applications that contain hexavalent chromium are an exception (Federal Acquisition Regulations System 2016).

In 2018, a Hexavalent Chromium Free Conversion Coatings Evaluation Consortium was established to identify, test, and evaluate various safer commercially available conversion coating materials. The consortium includes representatives from the following organizations: Blue Origin, Boeing, Lockheed Martin, National Aeronautics and Space Administration (NASA), Raytheon Technologies, Textron Aviation, and the Toxics Use Reduction Institute (TURI), at University of Massachusetts Lowell.

The goal of the project was to develop and execute a joint test protocol to comparatively evaluate commercially available hexavalent chromium-free conversion coating alternatives to an existing hexavalent chromium-containing baseline. Ultimately, the project aim was to provide the data necessary for each individual consortium member to justify the use of hexavalent chromiumfree conversion coatings for aerospace applications.

\section{MATERIAL AND METHODS}

A joint test protocol was developed by the consortium members to best evaluate the most recent and promising commercially available alternative conversion coatings. Based on the specifications covered, previous testing results, the primer types, and the corrosion inhibiting technology, the following conversion coating materials listed in Table 1 were selected for inclusion in the evaluation.

Table 1. Conversion coating materials and corrosion inhibitors.

\begin{tabular}{ccc}
\hline Supplier & Product & Corrosion inhibitor \\
\hline Henkel & Alodine 1200S & Hexavalent chromium (baseline for comparison) \\
\hline Chemeon & eTCP & Trivalent chromium \\
\hline PPG & DESOPREPTM 4000 & Zirconate \\
\hline PPG & RW-5562 & Trivalent chromium \\
\hline Socomore & Socosurf TCS/PACS & Trivalent chromium \\
\hline
\end{tabular}

\section{Test panels}

The aluminum alloy and tempers used for the test panels were 2024-T3, 6061-T6, 2219-T81, and 7075-T6. The four aluminum alloy/temper combinations selected for this evaluation are all used in the aerospace industry and represent varying alloy content. In general, the higher the copper content, the more challenging it is to meet corrosion requirements. Table 2 provides the copper content for each of the four aluminum alloy types used for this research. 
Table 2. Copper content of aluminum alloys.

\begin{tabular}{ccc}
\hline Alloy & Minimum copper concentration [\%] & Maximum copper concentration [\%] \\
\hline 6061 & 0.15 & 0.4 \\
\hline 7075 & 1.2 & 1.6 \\
\hline 2024 & 3.8 & 4.9 \\
\hline 2219 & 5.8 & 6.8 \\
\hline
\end{tabular}

There were two different test panel dimensions used for this research:

- 0.032 inches thick $\times 3$ inches wide $\times 10$ inches long;

- 0.020 inches thick $\times 3$ inches wide $\times 6$ inches long.

\section{Conversion coating application}

The conversion coatings were either applied in a controlled laboratory setting or in a production environment at a contracted metal finishing facility. The preference was to have the conversion coatings applied at a metal finishing facility instead of a laboratory setting to evaluate the robustness of the conversion coating application process with the inherent production variabilities within a metal finishing facility. In general, the chemical tanks were prepared as recommended by the Technical Data Sheet provided by the conversion coating manufacturer, and the conversion coatings were applied based on the MIL-DTL-5541 standard. All conversion coatings were air dried after application (MIL-DTL-5541 2006).

The Alodine 1200S and the Chemeon eTCP conversion coatings were applied at Poly-Metal Finishing, located in Springfield, Massachusetts, United States of America. Table 3 provides the processing steps used by Poly-Metal Finishing to apply the Alodine $1200 \mathrm{~S}$ conversion coating to the aluminum test panels.

Table 3. Alodine 1200 S processing steps.

\begin{tabular}{ccc}
\hline Description & Temperature (F) & Time \\
\hline Aluminum cleaner 164 (6 - 8 ounces per gallon) & $120-160$ & $10-12$ minutes \\
\hline Deionized (DI) water rinse & Ambient & $1-2$ minutes \\
\hline Bonderite C-IC 6 and 16 with nitric acid & Ambient & 10 minutes \\
\hline DI water rinse & Ambient & $1-2$ minutes \\
\hline Alodine 1200S (1 - 1.5 ounce per gallon) & $60-100$ & $1-3$ minutes \\
\hline DI water rinse & Ambient & $3-5$ minutes \\
\hline DI water rinse & $120-140$ & $10-15$ seconds \\
\hline
\end{tabular}

Table 4 provides the processing steps used by Poly-Metal Finishing to apply the Chemeon eTCP conversion coating to the aluminum test panels.

Table 4. Chemeon eTCP processing steps.

\begin{tabular}{ccc}
\hline Description & Temperature (F) & Time \\
\hline Aluminum cleaner 164 (6-8 ounces per gallon) & $120-160$ & $10-12$ minutes \\
\hline Deionized (DI) water rinse & Ambient & $1-2$ minutes \\
\hline Acid activated nitric acid (48-52\% volume) & Ambient & $60-70$ seconds \\
\hline Dl water rinse & Ambient & $1-2$ minutes \\
\hline Chemeon eTCP RTU (pH 3.6-4) & $68-78$ & $5-6$ minutes \\
\hline Dl water rinse & Ambient & $20-30$ seconds \\
\hline
\end{tabular}


The Socomore SocoSurf TCS/PACS conversion coating was applied to test panels at International Hardcoat, located in Detroit, Michigan, United States of America, using the processing steps listed in Table 5.

Table 5. SocoSurf TCS/PACS processing steps.

\begin{tabular}{ccc}
\hline Description & Temperature (F) & Time \\
\hline Sococlean A3432 (8- 12\%) & $95-131$ & 20 minutes \\
\hline Reverse osmosis (RO) water rinse & Ambient & $15-30$ seconds \\
\hline RO water rinse & Ambient & $15-30$ seconds \\
\hline Socosurf A1858 (30-50\%), Socosurf A1806 (6-15\%) & $104-140$ & 10 minutes \\
\hline RO water rinse & Ambient & $15-30$ seconds \\
\hline RO water rinse & Ambient & $15-30$ seconds \\
\hline Socosurf TCS (31 - 41\%) & $95-113$ & 10 minutes \\
\hline RO water rinse & Ambient & $15-30$ seconds \\
\hline RO water rinse & Ambient & $15-30$ seconds \\
\hline Ro water rinse & $68-86$ & 5 minutes \\
\hline RO water rinse & Ambient & $15-30$ seconds \\
\hline
\end{tabular}

The DESOPREP ${ }^{\mathrm{TM}} 4000$ and PPG RW-5562 conversion coatings were applied to test panels at the PPG Laboratory, located in Allison Park, Pennsylvania, United States of America, due to project time constraints and limited metal finisher capacity to apply the coatings. Table 6 provides the processing steps used by PPG to apply the PPG RW-5562 conversion coating.

Table 6. PPG RW-5562 processing steps.

\begin{tabular}{ccc}
\hline Description & Temperature (F) & Time \\
\hline Henkel Turco 6849 alkaline degreaser 20\% volume/volume & 140 & 10 minutes \\
\hline City water immersion rinse & 110 & 2.5 minutes \\
\hline City water immersion rinse & 110 & 2.5 minutes \\
\hline Deionized (DI) water spray rinse & Ambient & 5 seconds \\
\hline RW-7254 & Ambient & 2 minutes \\
\hline DI water spray rinse & Ambient & 30 seconds \\
\hline City water immersion rinse & Ambient & 2 minutes \\
\hline RW-5562 & Ambient & 6 minutes \\
\hline DI water immersion rinse & Ambient & 2 minutes \\
\hline DI water immersion rinse & Ambient & 2 minutes \\
\hline DI water spray rinse & Ambient & 5 seconds \\
\hline
\end{tabular}

Table 7 provides the processing steps used by PPG to apply the DESOPREP ${ }^{\mathrm{Tm}} 4000$ conversion coating to the aluminum test panels. 
Table 7. DESOPREPтм 4000 processing steps.

\begin{tabular}{ccc}
\hline Description & Temperature (F) & Time (minutes) \\
\hline Ultrax 5620D 10\% v/v & 110 & 2 \\
\hline City water immersion rinse & Ambient & 0.75 \\
\hline Deionized (DI) water immersion rinse & Ambient & 0.75 \\
\hline DESOPREPTM 4000 conversion coating & 85 & 2 \\
\hline City water immersion rinse & Ambient & 0.75 \\
\hline DI water immersion rinse & Ambient & 0.75 \\
\hline
\end{tabular}

\section{Coating weights}

Coating weight measurements were conducted by the following conversion coating processors: PolyMetal, International Hardcoat, and PPG, in accordance with MIL-DTL-81706 Para 4.5.4. The testing was done using 0.032 inch $\times 3$ inch $\times 10$ inch 2024 , 2219 , and 7075 aluminum alloy panels. Measurements were taken for a quantity of nine panels (three panels 2024, three panels 7075, and three panels 2219) for each type of conversion coating, excluding Zirconate DESOPREP ${ }^{\mathrm{TM}} 4000$. The three measurements for each conversion coating and aluminum alloy combination were averaged.

\section{Primer and topcoat application}

The primer and topcoat application was provided by CIL, located in Lawrence, Massachussets, United States of America. The non-hexavalent chromium primer used was PPG 02GN097, that may be a future candidate to qualify to MIL-PRF-23377 Type 1 Class N. PPG 02GN097 was chosen for its good corrosion resistance compared to other non-hexavalent chromium primers in the previous testing by consortium members. The non-hexavalent chromium topcoat used was PPG 03W127BF urethane color 17925 White that meets MIL-PRF-85285 Type 1 Class H.

The primer was spray applied per MIL-PRF-23377 Section 4.4.1, and the topcoat was spray applied per MIL-PRF-23377 Section 4.4.2 to one side of the panel. The primer and paint were applied as soon as possible upon receipt of panels from the conversion coating suppliers. The topcoat was applied on the same day as primer application and within $5 \mathrm{~h}$ of the primer application (MIL-PRF-23377 2012).

\section{Paint adhesion}

Paint adhesion testing using PPG 02GN097 primer was performed in accordance with MIL-DTL-5541 Para. 3.6.2 and MIL-DTL-81706 Para. 3.5.2. The aluminum alloys used for this test were 2024, 2219, 6061, and 7075. The test panel dimensions were 0.032 inch $\times 3$ inch $\times 10$ inch. Three separate wet tape adhesion tests were performed on each of the test panels, as follows:

- NPFC FED-STD-141 Method 6301.3 (parallel scribe required by MIL-DTL-5541);

- ASTM D3359 (Method A - “X” scribe required by MIL-DTL-81706);

- ASTM D3359 (Method B - cross-hatch).

ASTM D3359 Method B is a harsher test than Method A and helped to better differentiate performance between the different conversion coatings (NPFC 2001, MIL-DTL-81706 2004, ASTM International 2017).

\section{Electrical contact resistance}

Electrical contact resistance testing was performed in accordance with MIL-DTL-5541 Para. 4.6.1 and MIL-DTL-81706 Para. 4.5.5. Electrical contact resistance measurements were performed for ten test panels of alloy 6061 for each of four of the conversion coatings for a total of 40 panels. The test panel dimensions were 0.032 inch $\times 3$ inch $\times 10$ inch. The zirconate based DESOPREP ${ }^{\mathrm{rm}} 4000$ coating was not included. The 6061 panels were tested for electrical contact resistance before and after one week of exposure in neutral salt fog (NSF) per ASTM B117.

Electrical resistance panels were portioned similar to the layout provided in "MIL-DTL-81706 Para. 4.5.5. Figure 3" with a "Sharpie" pen and the numbers written on the edge of the panel. 


\section{Neutral salt fog corrosion resistance (bare aluminum)}

NSF corrosion resistance testing per ASTM B117 was performed in accordance with MIL-DTL-81706 Para. 4.5.1 and MIL-DTL-5541 Para. 4.4.1. This test provides a controlled corrosive environment to evaluate relative corrosion resistance of coated metals. The testing apparatus consists of a fog chamber, a salt solution reservoir, a supply of suitably conditioned air, atomizing nozzles, specimen supports, and heating elements. The salt solution shall be prepared by dissolving $5 \pm 1$ part by mass of sodium chloride in 95 parts of water. The aluminum alloys used for this test were 2024, 6061, and 7075. The test panel dimensions were 0.032 inch $\times 3$ inch $\times 10$ inch. Corrosion resistance was done for five panels of each alloy type and for four of the conversion coatings for a total of 60 panels. The panels only had conversion coatings and did not have any primer or topcoat. The zirconate based DESOPREP ${ }^{\mathrm{TM}} 4000$ was not included because it had no corrosion inhibitors.

The exposure was conducted for up to a 1,008-hour duration. The bare aluminum corrosion resistance testing was conducted at the Lockheed Martin Materials and Processes Laboratory, located in Fort Worth, Texas, United States of America.

\section{Neutral salt fog corrosion resistance (painted test panels)}

NSF testing per ASTM B117 on painted panels was performed using PPG 02GN097 primer only on some test panels, and both PPG 02GN097 primer and PPG 03W127BF topcoat on other test panels. The test panels' dimensions were 0.020 inches $\times 3$ inches $\times 6$ inches, and the 2024, 2219, 6061, and 7075 aluminum alloy panels were X scribed. The panels were exposed for 2,000 h in neutral salt spray. Visual inspections of the test panels during neutral salt spray tests were conducted every $500 \mathrm{~h}$. The NSF corrosion resistance testing was conducted at the Lockheed Martin Materials and Processes Laboratory. Figure 1 shows the test panels inside the NSF chamber (ASTM International 2016).

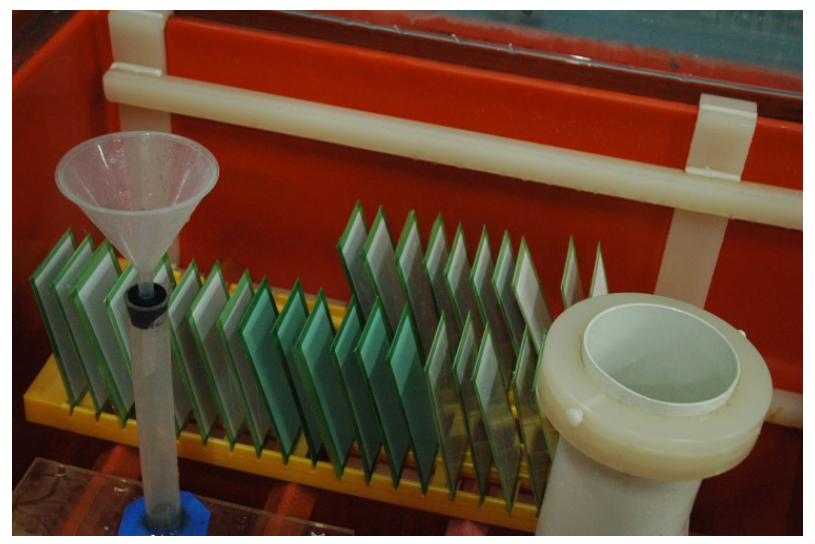

Figure 1. Test panels inside the neutral salt fog chamber.

\section{$\mathrm{SO}_{2}$ salt fog corrosion resistance (painted test panels]}

$\mathrm{SO}_{2}$ salt fog testing per ASTM G85 A4 were performed on painted panels using PPG 02GN097 primer only on some test panels and both PPG 02 GN097 primer and PPG 03W127BF topcoat on other test panels (ASTM International 2019b). The test panel dimensions were 0.020 inches $\times 3$ inches $\times 6$ inches, and the 2024, 2219,6061, and 7075 aluminum alloy panels were X scribed. The panels were exposed for $2,000 \mathrm{~h}$ in $\mathrm{SO}_{2}$ salt fog. The $\mathrm{SO}_{2}$ salt fog corrosion resistance testing was conducted at the Lockheed Martin Materials and Processes Laboratory.

\section{Beachfront corrosion testing}

The beachfront corrosion testing was conducted at the NASA Beachside Atmospheric Corrosion Test Site, at Kennedy Space Center, in Florida, United States of America, and commenced in December 2020. The long-term testing area is located at latitude $28.7^{\circ} \mathrm{N}$, longitude $80.6^{\circ} \mathrm{W}$ and at 150 feet from the mean high tide line of the Atlantic Ocean. Test coupons are oriented at a 30 -degree angle with respect to the horizontal. The test panels were exposed to high salt, high humidity, and high ultraviolet Florida seacoast environment. NASA measured corrosion rates and chloride concentrations on an ongoing basis at the test site (NASA 2021). 
The total duration for beachfront testing of the conversion coating test panels will be a minimum of 12 months. Visual inspections occurred at three-month intervals, and the nine-month test results are included in this paper. Photographs of the test panels and evaluation of the test panels occurred during the inspections. During these evaluations, the rate of the maximum creep from the scribe was determined as outlined in ASTM D1654 Procedure A. For the beachfront corrosion testing, there were 120 panels total included, with six panels per each aluminum alloy and conversion coating combination. All six panels for the DESOPREP ${ }^{\mathrm{TM}} 4000$, PPG RW-5562, and Socomore TCS/PACS conversion coatings had both primer and topcoat. For the Alodine 1200 and Chemeon eTCP coatings, three panels had primer only, and three panels had both primer and topcoat.

\section{RESULTS AND DISCUSSION}

\section{Coating weights}

To meet qualification requirements listed in MIL-DTL-81706 Para. 3.6, Type I coatings (hexavalent chromium) must have a coating weight average greater than $40 \mathrm{mg} / \mathrm{ft}^{2}$ on 2024 panels, and Type II coatings (non-hexavalent chromium) must have a coating weight average greater than $10 \mathrm{mg} / \mathrm{ft}^{2}$ (MIL-DTL-81706 2004).

The coating weights are provided in Table 8. All measurements for Type II coatings (non-hexavalent chromium) were more than the minimum required $10 \mathrm{mg} / \mathrm{ft}^{2}$ as stated in MIL-DTL-81706 Para. 3.6. Type I coatings (hexavalent chromium) were more than the minimum required, $40 \mathrm{mg} / \mathrm{ft}^{2}$, as stated in MIL-DTL-81706 Para. 3.6, except for the 2219 alloy for Alodine $1200 \mathrm{~S}$.

Table 8. Coating weight measurements.

\begin{tabular}{|c|c|c|c|c|}
\hline \multirow[b]{2}{*}{ Alloy } & \multicolumn{2}{|c|}{ Type I } & \multicolumn{2}{|c|}{ Type II } \\
\hline & $\begin{array}{l}\text { Alodine 1200s } \\
{\left[\mathrm{mg} / \mathrm{ft}^{2}\right]}\end{array}$ & $\begin{array}{c}\text { Chemeon eTCP } \\
{\left[\mathrm{mg} / \mathrm{ft}^{2}\right]}\end{array}$ & $\begin{array}{c}\text { PPG RW-5562 } \\
\left(\mathrm{mg} / \mathrm{ft}^{2}\right]\end{array}$ & $\begin{array}{c}\text { TCS/PACS } \\
{\left[\mathrm{mg} / \mathrm{ft}^{2}\right]}\end{array}$ \\
\hline 2024 & 49 & 39 & 51 & 52 \\
\hline 7075 & 42 & 39 & 62 & 42 \\
\hline 2219 & 33 & 24 & 36 & 48 \\
\hline
\end{tabular}

In yellow: the results for the conversion coating and aluminum alloy combinations that did not pass the coating weight requirement; in green: the results for the conversion coating and aluminum alloy combinations that did pass the coating weight requirement.

\section{Paint adhesion}

For the ASTM D3359 Method A, a score of 4A or higher is considered passing, as shown in Table 9, and for Method B a score of $4 \mathrm{~B}$ or higher is considered passing, as shown in Table 10. The results were averaged out over the multiple scribes. For the FEDSTD-141 method, there shall be no inter-coat separation between the paint system, the conversion coating, or the base metal.

Table 9. Method A adhesion scale per ASTM D3359.

\begin{tabular}{cc}
\hline Rating & Description \\
\hline $5 \mathrm{~A}$ & No peeling or removal \\
\hline $4 \mathrm{~A}$ & Trace peeling or removal along incisions or at their intersection \\
\hline $3 \mathrm{~A}$ & Jagged removal along incisions up to $1.6 \mathrm{~mm}$ on either side \\
\hline $2 \mathrm{~A}$ & Jagged removal along most of incisions up to $3.2 \mathrm{~mm}$ on either side \\
\hline $1 \mathrm{~A}$ & Removal from most of the area of the $\mathrm{X}$ under the tape \\
\hline OA & Removal beyond the area of the $\mathrm{X}$ \\
\hline
\end{tabular}


Table 10. Method B adhesion scale per ASTM D3359.

\begin{tabular}{cc}
\hline Rating & Description \\
\hline 5B & The edges of the cuts are completely smooth; none of the squares of the lattice is detached. \\
\hline 4B & Small flakes of the coating are detached at intersections; less than $5 \%$ of the area is affected. \\
\hline 3B & The coating has flaked along the edges and on parts of the squares. The area affected is 15 to $35 \%$ of the lattice. \\
\hline 2B & The coating has flaked along the edges of cuts in large ribbons and hole squares have detached. The area affected \\
is 35 to 65\% of the lattice.
\end{tabular}

Table 11 provides a summary of the paint adhesion test results.

Table 11. Paint adhesion test results.

\begin{tabular}{|c|c|c|c|c|c|c|c|c|c|c|c|c|}
\hline \multirow{2}{*}{$\begin{array}{c}\text { Conversion } \\
\text { coating }\end{array}$} & \multicolumn{3}{|c|}{2024} & \multicolumn{3}{|c|}{2219} & \multicolumn{3}{|c|}{6061} & \multicolumn{3}{|c|}{7075} \\
\hline & B & A & PS & B & A & PS & B & A & PS & B & A & PS \\
\hline 12005 & 4.2 & 4.3 & $\mathrm{P}$ & 4.3 & 4.5 & $\mathrm{P}$ & 5.0 & 5.0 & $\mathrm{P}$ & 4.0 & 4.5 & $\mathrm{P}$ \\
\hline TCS/PACS & 4.3 & 4.2 & $\mathrm{P}$ & 4.8 & 5.0 & $\mathrm{P}$ & 4.5 & 4.7 & $\mathrm{P}$ & 3.8 & 4.3 & $P$ \\
\hline eTCP & 3.2 & 3.8 & $\mathrm{P}$ & 3.2 & 3.5 & $\mathrm{P}$ & 3.2 & 3.3 & $\mathrm{P}$ & 3.3 & 3.7 & $P$ \\
\hline PPG RW-5562 & 4.5 & 4.5 & $\mathrm{P}$ & 3.8 & 3.7 & $\mathrm{P}$ & 4.0 & 4.0 & $P$ & 4.5 & 5.0 & $\mathrm{~F}$ \\
\hline DESOPREPTM & 3.5 & 4.0 & $\mathrm{~F}$ & 4.5 & 4.2 & $P$ & 3.8 & 4.0 & $\mathrm{P}$ & 2.2 & 3.0 & $\mathrm{~F}$ \\
\hline
\end{tabular}

A: Method A test results; B: Method B test results; PS: parallel scribe test results; in yellow: the results for the conversion coating and aluminum alloy combinations that did not pass the adhesion requirement; in green: the results for the conversion coating and aluminum alloy combinations that did pass the adhesion requirement.

The Alodine 1200S was the only type of conversion coating that passed Method A, Method B, and Parallel Scribe tests for all four alloy types. The SocoSurf TCS/PACS conversion coating passed Method A, Method B, and Parallel Scribe tests for all four alloy types, with one exception of Method B, for the 7075 alloy. The other three conversion coatings (eTCP, DESOPREP ${ }^{\mathrm{TM}} 4000$, and PPG RW-5562) had mixed results for Method A, Method B, and Parallel Scribe tests across all four alloy types.

Since Method A is required by MIL-DTL-81706, then this test is a good indicator of acceptability for defense applications. The Alodine 1200S and SocoSurfTCS/PACS conversion coatings passed Method A testing for all four alloy types. The PPG RW-5562 conversion coating passes Method A for all alloy types, except for 2219. The DESOPREP ${ }^{\mathrm{Tm}} 4000$ conversion coating passes Method A for all alloy types, except for 7075. The Chemeon eTCP conversion coating does not pass Method A for any of the four alloy types.

\section{Electrical contact resistance}

The failure criteria for this test was per MIL-DTL-5541 Para. 6.1.2.1 and MIL-DTL-81706 Para. 3.7, which require that the average electrical contact resistance measurement of each panel cannot be over $5 \mathrm{~m} \Omega$ pre-NSF or over $10 \mathrm{~m} \Omega$ post-NSF, and that no individual measurement on a panel can be $20 \%$ over the maximum values allowed. For pre-NSF, no individual reading can be over $6 \mathrm{~m} \Omega$. For post-NSF, no individual reading can be over $12 \mathrm{~m} \Omega$. Table 12 provides the results for the average electrical contact resistance measurements for each type of conversion coating.

Table 12. Electrical contact resistance measurement results.

\begin{tabular}{ccc}
\hline Conversion coating & Pre-NSF $(\mathrm{m} \Omega)$ & Post-NSF $(\mathrm{m} \Omega)$ \\
\hline Alodine 1200S & 3.17 & 5.46 \\
\hline Socosurf TCS/PACS & 3.92 & 6.96 \\
\hline Chemeon eTCP & 2.79 & 5.07 \\
\hline PPG RW-5562 & 2.98 & 5.96 \\
\hline
\end{tabular}

NSF: neutral salt fog; in green: results for the conversion coating that did pass the electrical contact resistance requirements. 
For pre-NSF, the average measurements for all four conversion coatings were not over $5 \mathrm{~m} \Omega$, and there were no individual readings above $6 \mathrm{~m} \Omega$ for all four conversion coatings. For post-NSF, the average measurements for all four conversion coatings were not over $10 \mathrm{~m} \Omega$, and there were no individual readings above $12 \mathrm{~m} \Omega$ for all four conversion coatings. Therefore, all four conversion coatings passed the requirements for electrical contact resistance.

\section{Neutral salt fog corrosion resistance (bare aluminum]}

To fulfill the qualification requirements in MIL-DTL-81706 Para. 3.5.1, the 2024 and 7075 panel groups must pass $336 \mathrm{~h}$ (two weeks) of NSF with no pitting. The failure criteria for this test was per MIL-DTL-5541 Para. 3.6.1, in which greater than five pits on at least one panel in the group or greater than 15 pits throughout the whole group of five panels after $168 \mathrm{~h}$. The panels were inspected at 168, 336, 504, and $672 \mathrm{~h}$. Figure 2 shows the Socosurf TCS/PACS conversion coating on 2024 alloy aluminum test panels at initial conditions $(0 \mathrm{~h}), 168$-h inspection, 336-h inspection, 504-h inspection, and 672-h inspection. The Socosurf TCS/PACS conversion coating passed all inspections including the 672-h inspection.

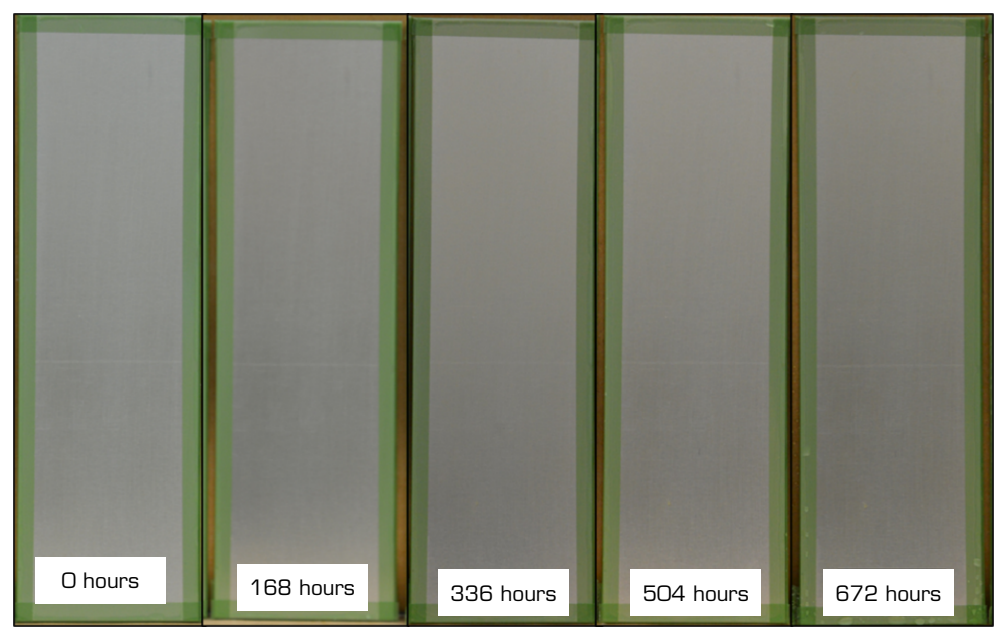

Figure 2. Neutral salt fog results on bare aluminum for Socosurf TCS/PACS on 2024 alloy.

Figure 3 shows the Chemeon eTCP conversion coating on 7075 alloy aluminum test panels at initial conditions ( $0 \mathrm{~h}), 168$-h inspection, 336-h inspection, and 504-h inspection. The Chemeon eTCP conversion coating failed during the 504-h inspection.

(a)

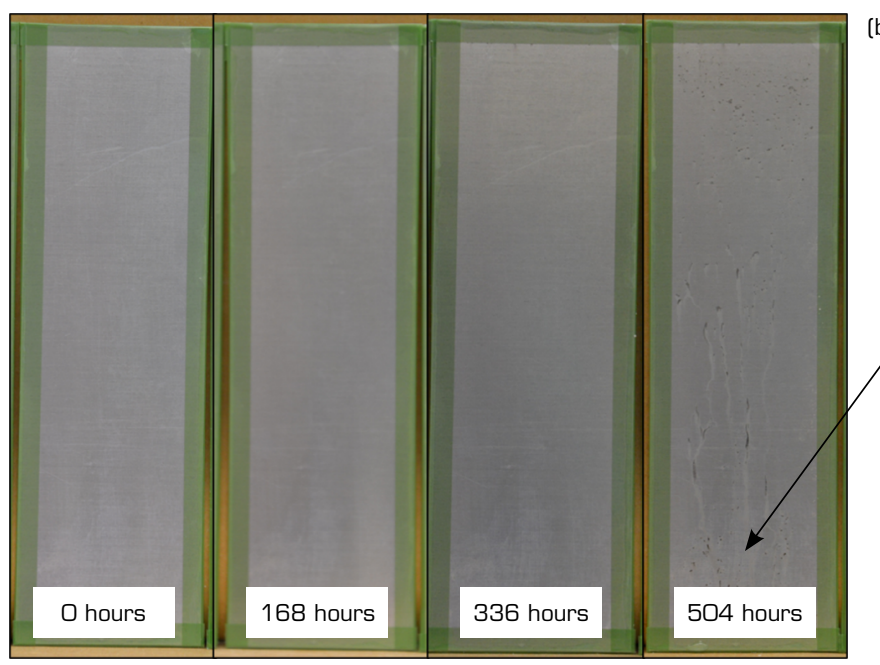

(b)

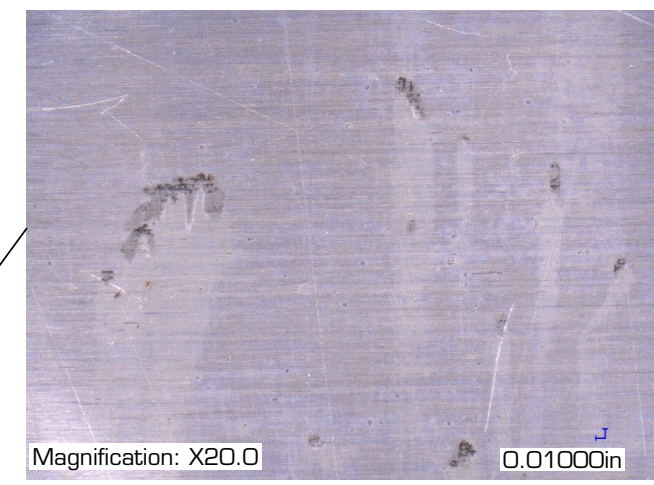

Figure 3. Neutral salt fog results on bare aluminum for Chemeon eTCP on 7075 alloy.

The results on bare aluminum are in Table 13 are for the conversion coating and aluminum alloy combinations that did pass the 336 hour requirement. 
Table 13. Neutral salt fog test results on bare aluminum.

\begin{tabular}{clll}
\hline Conversion coating & 2024 & 2219 & 7075 \\
\hline Alodine 1200S & Fail at 168 $\mathrm{h}$ & Fail at $168 \mathrm{~h}$ & Fail at 168 $\mathrm{h}$ \\
\hline Chemeon eTCP & Fail at 168 $\mathrm{h}$ & Fail at $168 \mathrm{~h}$ & Fail at $504 \mathrm{~h}$ \\
\hline PPG RW-5562 & Fail at 168 $\mathrm{h}$ & Fail at $336 \mathrm{~h}$ & Fail at $504 \mathrm{~h}$ \\
\hline Socosurf TCS/PACS & Fail at 672 $\mathrm{h}$ & Fail at 672 $\mathrm{h}$ & Passed 672 $\mathrm{h}$ \\
\hline
\end{tabular}

In yellow: the results for the conversion coating and aluminum alloy combinations that did not pass the 336-hour requirement; in green: the results for the conversion coating and aluminum alloy combinations that did pass the 336 -hour requirement.

The Socosurf TCS/PACS conversion coating had the best performance and passed the 336-hour requirement with no pitting for the 2024, 2219, and 7075 test panels. The Chemeon eTCP and PPG RW-5562 conversion coatings had the next best performance by passing the 336-hour requirement with no pitting for the 7075 alloy. However, the Chemeon eTCP and PPG RW-5562 conversion coatings did not pass for the 2024 and 2219 test panels. The Alodine 1200 S conversion coating had the worst performance and did not pass for any of the three aluminum alloy types.

\section{Neutral salt fog corrosion resistance [painted test panels]}

To meet the minimum ASTM B117 specifications requirements, there must be no signs of corrosion within the group of three panels after 2,000 h of NSF exposure. Success is defined as no blistering, lifting/bubbling of either coating, nor substrate pitting and no white corrosion or pitting in the scribe. Figure 4 shows the PPG RW-5562 conversion coating on 2024 aluminum alloy test panels at initial conditions $(0 \mathrm{~h}$ ), 500-h inspection, 1,000-h inspection, 1,500-h inspection, and 2,000-h inspection. The panels failed at the 1,000-h inspection, and the photos at the 1,500- and 2,000-h inspections show the further propagation of corrosion on the test panels.

(a)

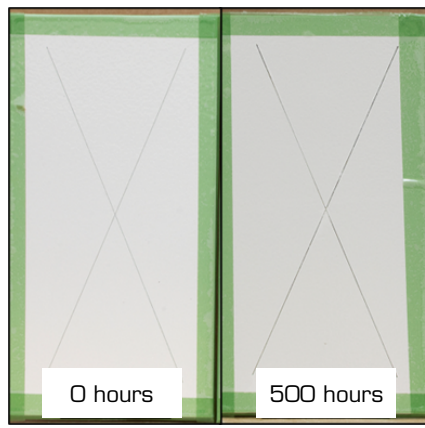

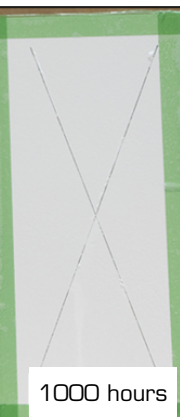

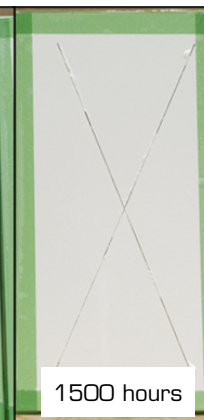

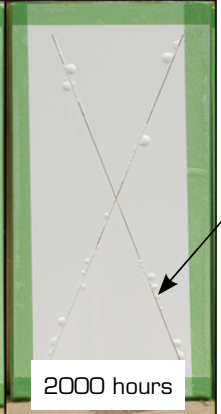

(b)

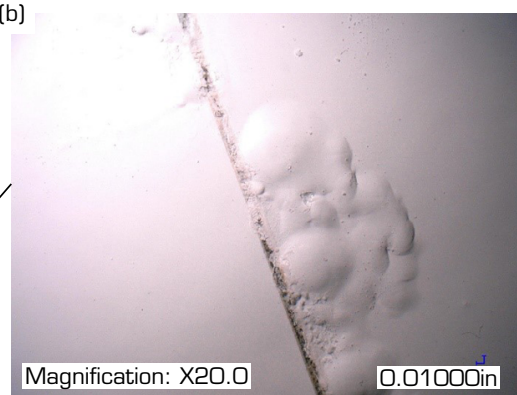

Figure 4. Neutral salt fog results on painted coupons for PPG RW-5562 on 2024 aluminum alloy test panels.

Table 14 shows the results of the inspections during visual inspections at 500, 1,000, 1,500, and 2,000 $\mathrm{h}$.

Table 14. Neutral salt fog corrosion resistance results on painted coupons.

\begin{tabular}{|c|c|c|c|c|c|}
\hline Conversion coating & Coating & 2024 & 2219 & 6061 & 7075 \\
\hline Alodine 1200 & $\begin{array}{l}\text { Primer and } \\
\text { topcoat }\end{array}$ & $\begin{array}{c}\text { Fail } \\
1,000 \mathrm{~h}\end{array}$ & $\begin{array}{c}\text { Fail } \\
500 \mathrm{~h}\end{array}$ & $\begin{array}{c}\text { Pass } \\
2,000 \mathrm{~h}\end{array}$ & $\begin{array}{c}\text { Fail } \\
1,500 \mathrm{~h}\end{array}$ \\
\hline Chemeon eTCP & $\begin{array}{l}\text { Primer and } \\
\text { topcoat }\end{array}$ & $\begin{array}{c}\text { Fail } \\
1,000 \mathrm{~h}\end{array}$ & $\begin{array}{c}\text { Fail } \\
500 \mathrm{~h}\end{array}$ & $\begin{array}{c}\text { Pass } \\
2,000 \mathrm{~h}\end{array}$ & $\begin{array}{c}\text { Fail } \\
500 \mathrm{~h}\end{array}$ \\
\hline Socosurf TCS/PACS & $\begin{array}{l}\text { Primer and } \\
\text { topcoat }\end{array}$ & $\begin{array}{c}\text { Fail } \\
500 \mathrm{~h}\end{array}$ & $\begin{array}{c}\text { Fail } \\
500 \mathrm{~h}\end{array}$ & $\begin{array}{c}\text { Pass } \\
2,000 \mathrm{~h}\end{array}$ & $\begin{array}{c}\text { Fail } \\
500 \mathrm{~h}\end{array}$ \\
\hline PPG RW-5562 & $\begin{array}{l}\text { Primer and } \\
\text { topcoat }\end{array}$ & $\begin{array}{c}\text { Fail } \\
500 \mathrm{~h}\end{array}$ & $\begin{array}{c}\text { Fail } \\
500 \mathrm{~h}\end{array}$ & $\begin{array}{c}\text { Pass } \\
2,000 \mathrm{~h}\end{array}$ & $\begin{array}{c}\text { Fail } \\
1,000 \mathrm{~h}\end{array}$ \\
\hline PPG DESOPREP'M 4000 & $\begin{array}{l}\text { Primer and } \\
\text { topcoat }\end{array}$ & $\begin{array}{c}\text { Fail } \\
500 \mathrm{~h}\end{array}$ & $\begin{array}{c}\text { Fail } \\
500 \mathrm{~h}\end{array}$ & $\begin{array}{c}\text { Pass } \\
2,000 \mathrm{~h}\end{array}$ & $\begin{array}{c}\text { Fail } \\
500 \mathrm{~h}\end{array}$ \\
\hline Alodine 12005 & Primer only & $\begin{array}{c}\text { Pass } \\
2,000 \mathrm{~h}\end{array}$ & $\begin{array}{c}\text { Fail } \\
500 \mathrm{~h}\end{array}$ & $\begin{array}{c}\text { Pass } \\
2,000 \mathrm{~h}\end{array}$ & $\begin{array}{c}\text { Fail } \\
500 \mathrm{~h}\end{array}$ \\
\hline Chemeon eTCP & Primer only & $\begin{array}{c}\text { Fail } \\
1,000 \mathrm{~h}\end{array}$ & $\begin{array}{c}\text { Fail } \\
500 \mathrm{~h}\end{array}$ & $\begin{array}{c}\text { Pass } \\
2,000 \mathrm{~h}\end{array}$ & $\begin{array}{c}\text { Fail } \\
500 \mathrm{~h}\end{array}$ \\
\hline
\end{tabular}

In yellow: results for the conversion coatings that did not pass the 2,000 -h requirement; in green: results for the conversion coatings that did pass the 2,000-h requirement. 
All five types of conversion coating passed the 2,000-h requirement for the test panels with 6061 alloy. Alodine $1200 \mathrm{~S}$ was the only conversion coating that passed the 2,000-h requirement for the test panels with 2024 alloy. Any of the five types of conversion coating did not pass the 2,000-h requirement for the test panels with 7075 and 2219 alloys.

\section{$\mathrm{SO}_{2}$ salt fog corrosion resistance (painted test panels)}

To meet the minimum requirements for the $\mathrm{SO}_{2}$ salt fog corrosion resistance test, there should be no signs of corrosion within the group of three panels after $336 \mathrm{~h}$ of exposure. The panels were inspected at $168 \mathrm{~h}, 336 \mathrm{~h}$, and $504 \mathrm{~h}$. Figure 5 shows the DESOPREP ${ }^{\mathrm{TM}} 4000$ conversion coating on the 2219 test panels at initial conditions $(0 \mathrm{~h}), 168 \mathrm{~h}$, and $336 \mathrm{~h}$. The DESOPREP ${ }^{\mathrm{TM}}$ 4000 conversion coating failed at the 168 -h inspection, and the photo at the 336 -h inspection shows the further propagation of corrosion on the test panel.

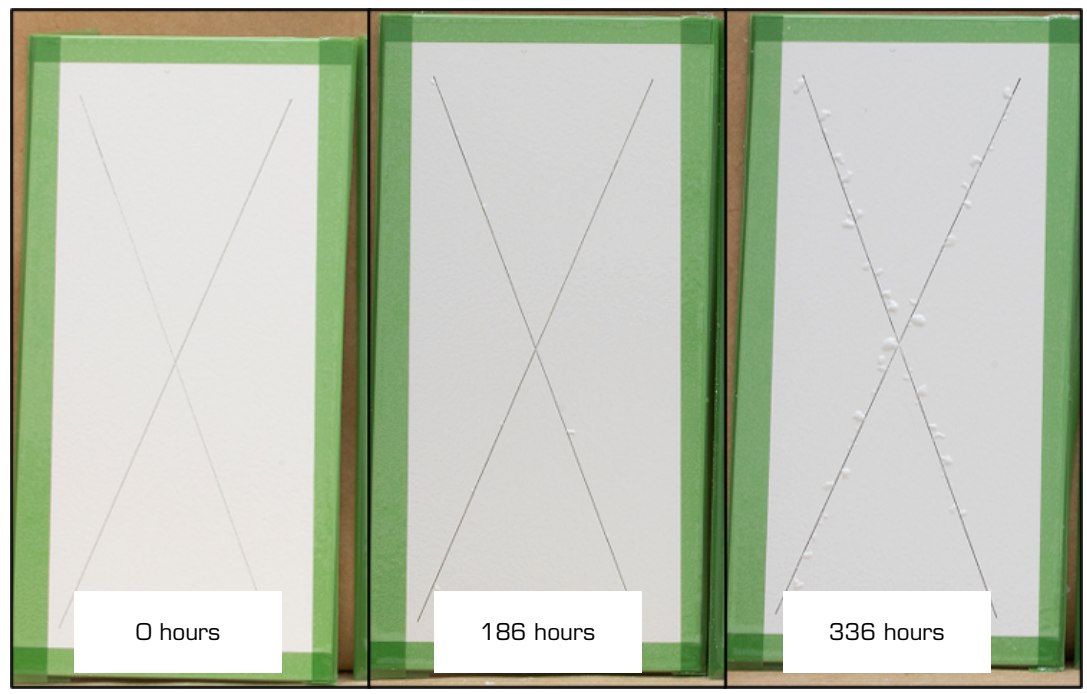

Figure 5. $\mathrm{SO}_{2}$ salt fog corrosion resistance for DESOPREP ${ }^{\mathrm{TM}} 4000$ on 2219 alloy.

Table 15 shows the results of the inspections for the $\mathrm{SO}_{2}$ salt fog corrosion resistance test.

Table 15. $\mathrm{SO}_{2}$ salt fog corrosion resistance results on painted coupons.

\begin{tabular}{|c|c|c|c|c|c|}
\hline $\begin{array}{c}\text { Conversion } \\
\text { Coating }\end{array}$ & Coating & 2024 & 2219 & 6061 & 7075 \\
\hline Alodine 1200 & $\begin{array}{l}\text { Primer and } \\
\text { topcoat }\end{array}$ & Fail at $504 \mathrm{~h}$ & Fail at $168 \mathrm{~h}$ & $\begin{array}{l}\text { Fail at } \\
336 \mathrm{~h}\end{array}$ & Fail at $336 \mathrm{~h}$ \\
\hline Chemeon eTCP & $\begin{array}{l}\text { Primer and } \\
\text { topcoat }\end{array}$ & Fail at $504 \mathrm{~h}$ & Fail at $168 \mathrm{~h}$ & $\begin{array}{l}\text { Fail at } \\
336 \mathrm{~h}\end{array}$ & Fail at $504 \mathrm{~h}$ \\
\hline Socosurf TCS/PACS & $\begin{array}{l}\text { Primer and } \\
\text { topcoat }\end{array}$ & Fail at $504 \mathrm{~h}$ & Fail at $168 \mathrm{~h}$ & $\begin{array}{l}\text { Fail at } \\
336 \mathrm{~h}\end{array}$ & Fail at $336 \mathrm{~h}$ \\
\hline PPG RW-5562 & $\begin{array}{l}\text { Primer and } \\
\text { topcoat }\end{array}$ & Fail at $504 \mathrm{~h}$ & Fail at $168 \mathrm{~h}$ & $\begin{array}{l}\text { Fail at } \\
336 \mathrm{~h}\end{array}$ & Fail at $336 \mathrm{~h}$ \\
\hline $\begin{array}{c}\text { PPG DESOPREPTM } \\
4000\end{array}$ & $\begin{array}{l}\text { Primer and } \\
\text { topcoat }\end{array}$ & Fail at $504 \mathrm{~h}$ & Fail at $168 \mathrm{~h}$ & $\begin{array}{l}\text { Fail at } \\
336 \mathrm{~h}\end{array}$ & Fail at $336 \mathrm{~h}$ \\
\hline Alodine 1200s & Primer only & Fail at $504 \mathrm{~h}$ & Fail at $168 \mathrm{~h}$ & $\begin{array}{l}\text { Fail at } \\
336 \mathrm{~h}\end{array}$ & No failure \\
\hline Chemeon eTCP & Primer only & Fail at $336 \mathrm{~h}$ & Fail at $168 \mathrm{~h}$ & $\begin{array}{l}\text { Fail at } \\
336 \mathrm{~h}\end{array}$ & No failure \\
\hline
\end{tabular}

In yellow: results for the conversion coating and aluminum alloy combinations that did not pass the 336-h requirement; in green: results for the conversion coating and aluminum alloy combinations that did pass the 336-h requirement. 
All conversion coatings failed at $168 \mathrm{~h}$ for the 2219 alloy and at $336 \mathrm{~h}$ for the 6061 alloy. All conversion coatings, apart from Chemeon eTCP primer only, passed the 336-h requirement for the 2024 alloy. Chemeon eTCP had the best performance for the 7075 alloy by passing the 336-h requirement with primer and topcoat, and having no failure at $504 \mathrm{~h}$ for the primer only panels.

\section{Beachfront corrosion testing}

The maximum creep from the scribe during beachfront corrosion testing was determined as outlined in ASTM D1654 Procedure A. The ratings used for the creep distance from the scribe are shown in Table 16.

Table 16. Rating of failure at scribe for procedure A.

\begin{tabular}{ccc}
\hline & Representative mean creepage from scribe & \\
\hline Millimeters & Inches (approximate) & Rating number \\
\hline Zero & 0 & 10 \\
\hline Over 0 to 0.5 & 0 to $1 / 64$ & 9 \\
\hline Over 0.5 to 1 & $1 / 64$ to $1 / 32$ & 7 \\
\hline Over 1 to 2 & $1 / 32$ to $1 / 16$ & 6 \\
\hline Over 2 to 3 & $1 / 16$ to $1 / 8$ & 4 \\
\hline Over 3 to 5 & $1 / 8$ to $3 / 16$ & 3 \\
\hline Over 5 to 7 & $3 / 16$ to $1 / 4$ & 2 \\
\hline Over 7 to 10 & $1 / 4$ to $3 / 8$ & 1 \\
\hline Over 10 to 13 & $3 / 8$ to $1 / 2$ & 0 \\
\hline Over 13 to 16 & $1 / 2$ to $5 / 8$ & 5 \\
\hline Over 16 to more & $5 / 8$ to more & \\
\hline
\end{tabular}

A representative photograph of the beachfront corrosion test after nine months is provided in Fig. 6. The photograph is of the DESOPREP $^{\mathrm{TM}} 4000$ conversion coating on alloy 2024 test panel \#1, which has a rating of 3 , indicating that corrosion had creeped between 7 to $10 \mathrm{~mm}$ from the scribe area.

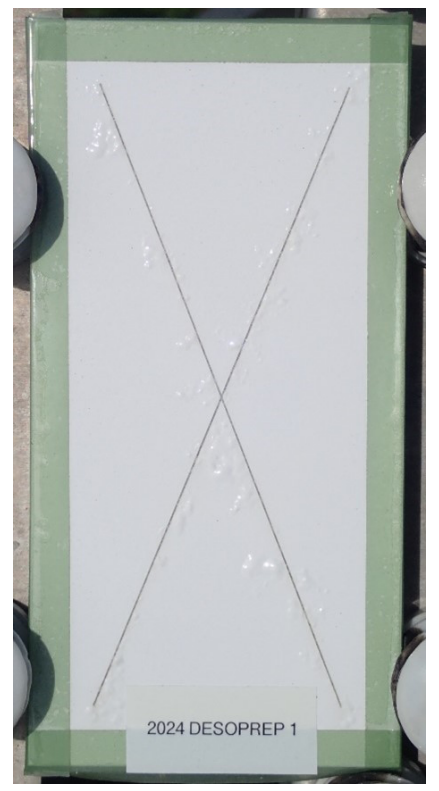

Figure 6. DESOPREP ${ }^{\mathrm{TM}} 4000$ on 2024 alloy test panel \#1 after nine months beachfront exposure. 
Table 17 provides the ratings for each of the test panels at the nine-month visual inspection.

Table 17. Beachfront visual inspection after nine months of exposure.

\begin{tabular}{|c|c|c|c|c|}
\hline Conversion coating & 2219 & 2024 & 7075 & 6061 \\
\hline $1200 S$ PS1-1 & 10 & 10 & 10 & 10 \\
\hline 1200S PS1-2 & 10 & 10 & 10 & 10 \\
\hline 1200S PS1-3 & 10 & 10 & 10 & 10 \\
\hline $1200 \mathrm{~S}$ TC-1 & 9 & 10 & 10 & 10 \\
\hline 1200S TC-2 & 7 & 10 & 10 & 10 \\
\hline 12005 TC-3 & 7 & 10 & 10 & 10 \\
\hline eTCP P-1 & 10 & 10 & 10 & 10 \\
\hline еТСР P-2 & 10 & 10 & 10 & 10 \\
\hline eTCP P-3 & 10 & 10 & 10 & 10 \\
\hline eTCP TC-1 & 7 & 10 & 10 & 10 \\
\hline еTCP TC-2 & 8 & 10 & 10 & 10 \\
\hline еTCP TC-3 & 7 & 10 & 10 & 10 \\
\hline PPG RW-5562-1 & 5 & 10 & 10 & 10 \\
\hline PPG RW-5562-2 & 6 & 10 & 10 & 10 \\
\hline PPG RW-5562-3 & 7 & 10 & 10 & 10 \\
\hline PPG RW-5562-4 & 6 & 10 & 10 & 10 \\
\hline PPG RW-5562-5 & 6 & 10 & 10 & 10 \\
\hline PPG RW-5562-6 & 6 & 10 & 10 & 10 \\
\hline DESOPREPTM TC-1 & 2 & 3 & 3 & 10 \\
\hline DESOPREPTM TC-2 & 3 & 1 & 3 & 10 \\
\hline DESOPREPTM TC-3 & 3 & 3 & 4 & 10 \\
\hline DESOPREPTM TC-4 & 1 & 3 & 3 & 5 \\
\hline DESOPREPTM TC-5 & 1 & 2 & 3 & 7 \\
\hline DESOPREPTM TC-6 & 3 & 3 & 2 & 10 \\
\hline Socosurf TCS/PACS-1 & 7 & 10 & 10 & 10 \\
\hline Socosurf TCS/PACS-2 & 6 & 10 & 10 & 10 \\
\hline Socosurf TCS/PACS-3 & 9 & 10 & 10 & 10 \\
\hline Socosurf TCS/PACS-4 & 6 & 10 & 10 & 10 \\
\hline Socosurf TCS/PACS-5 & 8 & 10 & 10 & 10 \\
\hline Socosurf TCS/PACS-6 & 7 & 10 & 10 & 10 \\
\hline
\end{tabular}

In yellow: results for the conversion coating and aluminum alloy combinations that did not pass the beachfront corrosion testing requirement; in green: results for the conversion coating and aluminum alloy combinations that did pass the beachfront corrosion testing requirement.

For the 2024, 6061, and 7075 aluminum alloys, all conversion coatings achieved the rating of 10, except for the DESOPREP ${ }^{\mathrm{rm}} 4000$ conversion coating. For the 2219 panels, the highest levels of corrosion were observed. Any of the five types of conversion coatings with primer and topcoat did not achieve a rating of 10. However, the Alodine 1200 S and Chemeon eTCP conversion coatings with primer only did achieve the rating of 10 for the 2219 panels. As the beachfront exposure continues, this test looks like it will be a great identifier to distinguish the corrosion resistance of the conversion coating candidates. 


\section{Summary}

A summary of the results from the various tests conducted during this evaluation are provided in Table 18.

Table 18. Summary of all testing results.

\begin{tabular}{|c|c|c|c|c|c|c|c|}
\hline Coating \& alloy & $\begin{array}{l}\text { Coating } \\
\text { weight }\end{array}$ & Adhesion & Electrical & NSF bare & $\begin{array}{c}\text { NSF } \\
\text { painted }\end{array}$ & $\begin{array}{c}\mathrm{SO}_{2} \\
\text { painted }\end{array}$ & $\begin{array}{c}\text { Beach- } \\
\text { front }\end{array}$ \\
\hline Alodine 6061 & Not tested & Pass & Pass & Not tested & Pass & Fail & Pass \\
\hline Alodine 7075 & Pass & Pass & Not tested & Fail & Fail & Fail & Pass \\
\hline Alodine 2024 & Pass & Pass & Not tested & Fail & Fail & Pass & Pass \\
\hline Alodine 2219 & Fail & Pass & Not tested & Fail & Fail & Fail & Fail \\
\hline DESOPREP'т 6061 & Not tested & Pass & Pass & Not tested & Pass & Fail & Fail \\
\hline DESOPREP'T 7075 & Not tested & Fail & Not tested & Not tested & Fail & Fail & Fail \\
\hline DESOPREP'м 2024 & Not tested & Pass & Not tested & Not tested & Fail & Pass & Fail \\
\hline DESOPREPTм 2219 & Not tested & Pass & Not tested & Not tested & Fail & Fail & Fail \\
\hline еTCP 6061 & Not tested & Fail & Pass & Not tested & Pass & Fail & Pass \\
\hline eTCP 7075 & Pass & Fail & Not tested & Pass & Fail & Pass & Pass \\
\hline еTCP 2024 & Pass & Fail & Not tested & Fail & Fail & Pass & Pass \\
\hline еTCP 2219 & Pass & Fail & Not tested & Fail & Fail & Fail & Fail \\
\hline PPG RW-5562 6061 & Not tested & Pass & Pass & Not tested & Pass & Fail & Pass \\
\hline PPG RW-5562 7075 & Pass & Pass & Not tested & Pass & Fail & Fail & Pass \\
\hline PPG RW-5562 2024 & Pass & Pass & Not tested & Fail & Fail & Pass & Pass \\
\hline PPG RW-5562 2219 & Pass & Fail & Not tested & Fail & Fail & Fail & Fail \\
\hline Socosurf 6061 & Not tested & Pass & Pass & Not tested & Pass & Fail & Pass \\
\hline Socosurf 7075 & Pass & Pass & Not tested & Pass & Fail & Fail & Pass \\
\hline Socosurf 2024 & Pass & Pass & Not tested & Pass & Fail & Pass & Pass \\
\hline Socosurf 2219 & Pass & Pass & Not tested & Pass & Fail & Fail & Fail \\
\hline
\end{tabular}

NSF: neutral salt fog; in yellow: results for the conversion coating and aluminum alloy combinations that did not pass the test requirement; in green: results for the conversion coating and aluminum alloy combinations that did pass the test requirement.

The test results for the four conversion coatings without hexavalent chromium was encouraging. Several stringent tests were passed for each of the conversion coatings.

The four aluminum alloys used for this evaluation have varying levels of copper content. In general, the higher the copper content, the more challenging it is anticipated to meet corrosion requirements. However, this trend was not observed with the $\mathrm{SO}_{2}$ salt fog testing, in which the 2024 outperformed both the 7075 and 6061, despite having a higher copper content alloy. This result highlights the complexity of corrosion and why multiple different tests are needed to fully evaluate performance.

The same corrosion tests were not done for all alloys. The NSF bare aluminum corrosion testing was not done for the 6061 alloy, but it was done for the 7075, 2024, and 2219 alloys. To provide a fair comparison across all alloy types, the NSF bare aluminum was excluded. However, the following three corrosion tests were conducted for all five conversion coatings and four types of aluminum alloys: NSF painted corrosion testing, $\mathrm{SO}_{2}$ painted corrosion testing, and beachfront corrosion testing. For the 6061 alloy with $0.41 \%$ copper, the results of the five different conversion coatings were a pass rate of 10 of the 15 corrosion tests or a pass rate of $67 \%$. For the 2219 alloy with $6.8 \%$ copper, the results of the five different conversion coatings were a pass rate of 0 of the 15 corrosion tests or a pass rate of $0 \%$. These results are consistent with the anticipated greater difficulty of corrosion protection with increasing amounts of copper within the aluminum alloy. 
Hexavalent chromium-based conversion coatings commonly pass salt fog corrosion tests. However, the Alodine $1200 \mathrm{~S}$ conversion coating did not pass NSF test on bare aluminum for the 7075, 2024, and 2219 alloys. Passage of this test is required by MIL-DTL-5541 as part of monthly process control inspection, so this failure was unexpected.

The Alodine 1200S did not pass the $\mathrm{SO}_{2}$ salt fog test for the 6061, 7075, and 2219 alloys; and did not pass the NSF test for painted coupons for the 7075, 2024, and 2219 alloys. The test results of the Alodine 1200S conversion coating demonstrate the importance of proper panel pre-treatment and conversion coating application procedures at metal finishing facilities to obtain passing results. Further, it shows that a conversion coating applied at a metal finishing facility may not pass the tests. However, the conversion coating could pass if proper panel pre-treatment and conversion coating application procedures are followed.

The hexavalent chromium-free conversion coating with the best results for the 2024 alloy was the Socosurf TCS/PACS, since it was the only alternative conversion coating that passed requirements including coating weight, paint adhesion, NSF bare aluminum corrosion test, $\mathrm{SO}_{2}$ painted corrosion test, and beachfront corrosion test. The hexavalent chromium-free conversion coating with the best results for the 2019 alloy was the Socosurf TCS/PACS, as it was the only alternative conversion coating that passed the coating weight, paint adhesion, and NSF bare aluminum corrosion test.

For the 6061 alloy, the Socosurf TCS/PACS, PPG RW-5562, and DESOPREP ${ }^{\mathrm{TM}} 4000$ all had similar performance by passing the paint adhesion, electrical contact resistance, and NSF painted corrosion test. For the 7075 alloy, the Socosurf TCS/PACS, PPG RW-5562, and Chemeon eTCP each passed four of the evaluation tests.

\section{CONCLUSIONS}

Overall, the Socosurf TCS/PACS was the best performing hexavalent chromium-free conversion coating across all four types of aluminum alloy. It had the best or tied for the best performance for each alloy type. In addition, the Socosurf TCS/PACS was applied at a metal finisher facility, which further demonstrates its robustness as an alternative conversion coating. Other conversion coatings without hexavalent chromium such as PPG RW-5562, Chemeon eTCP, and DESOPREP ${ }^{\mathrm{mm}} 4000$ demonstrated success by passing several industry standard tests. The superior performance of the TCS/PACS over the other trivalent-based coatings is attributable to the effects of the final peroxide bath, which has been shown to convert a nano-scale layer of trivalent chromium to hexavalent chromium on the surface. However, the amount of hexavalent chromium is so minute that the resulting coating may be considered hexavalent chromium free for all practical and regulatory purposes.

The coatings performed well on 6061, with all passing painted NSF and beachfront testing, with only the eTCP having any adhesion issues. This alloy is intrinsically more corrosion resistant than the other alloys included in this evaluation. However, its lower tensile strength limits its use in many critical aerospace applications. This low copper containing alloy is a clear candidate for use of non-hexavalent chromium coatings.

No single evaluation will completely resolve the long-standing issue of replacing hexavalent chromium in conversion coatings with a safer alternative, but the results of this evaluation provide significant progress to achieving that goal since numerous hexavalent chromium-free conversion coatings passed several qualification tests for various aluminum alloys.

Further research is needed to evaluate why all types of conversion coatings did not pass the NSF painted coupon corrosion tests. Also, the beachfront corrosion test results at the 12-month interval will provide further data about the long term corrosion resiliency of the alternative conversion coatings to ambient conditions.

\section{AUTHORS' CONTRIBUTIONS}

Conceptualization: Morose G., Pinsky D., and DeFranco K.; Funding Acquisition: Morose G., Pinsky D., and DeFranco K.; Methodology: Morose G., Pinsky D., and DeFranco K.; Resources: Pinsky D., and DeFranco K.; Supervision: Morose G.; Writing - Original Draft: Morose G., Humphrey C., and DeFranco K.; Writing - Review \& Editing: Morose G., Pinsky D., Humphrey C., and DeFranco K. 


\section{DATA AVAILABILITY STATEMENT}

The data that support the findings of this study are available on request from the corresponding author.

\section{FUNDING}

Not applicable.

\section{ACKNOWLEDGMENTS}

The authors acknowledge the contributions from Lockheed Martin Aeronautics and NASA for providing testing services; Textron Aviation and Blue Origin for providing aluminum test panels; and PPG for providing panels with PPG conversion coatings.

\section{REFERENCES}

Agency for Toxic Substances and Disease Registry (ATSDR) (2012) Toxicological profile for chromium. United States of America: ATSDR.

American Society for Testing and Materials (ASTM International) (2016) ASTM D1654-08(2016)e1. Standard test method for evaluation of painted or coated specimens subjected to corrosive environments. West Conshohocken: ASTM International.

American Society for Testing and Materials (ASTM International) (2017) ASTM D3359-17. Standard test methods for rating adhesion by tape test. West Conshohocken: ASTM International.

American Society for Testing and Materials (ASTM International) (2019a) ASTM B117-19. Standard practice for operating salt spray (fog) apparatus. West Conshohocken: ASTM International.

American Society for Testing and Materials (ASTM International) (2019b) ASTM G85-19. Standard practice for modified salt spray (fog) testing. West Conshohocken: ASTM International.

Costa M, Klein C (2006) Toxicity and carcinogenicity of chromium compounds in humans. Rev Toxicol 36(2):155-163. https://doi.org/10.1080/10408440500534032

Federal Acquisition Regulations System (2016) Title 48. United States of America: Defense Acquisition Regulations System, Department of Defense. Part 222, p. 159-160.

International Agency for Research on Cancer (IARC) (2012) Monographs on the evaluation of carcinogenic risks to humans. United States of America: IARC. v. 100C.

Kendig M, Jeanjaquet S, Addison R, and Waldrop J. (2001) Role of hexavalent chromium in the inhibition of corrosion of aluminum alloys. Surf Coat Technol 140(1):58-66. https://doi.org/10.1016/S0257-8972(01)01099-4

MIL-DTL-5541 (2006) Revision F, Military specification, chemical conversion coatings on aluminum and aluminum alloys, Paragraph 3.5. 
MIL-DTL-81706 (2004) Revision B, Chemical conversion materials for coating aluminum and aluminum alloys, Sections 3.6 and 4.5.4.

MIL-PRF-23377 (2012) Revision K, Performance specification: primer coatings: epoxy, high solids, Sections 4.4.1 and 4.4.2.

National Aeronautics and Space Administration (NASA) (2021) Corrosion Engineering Laboratory long-term atmospheric testing. United States of America: NASA. Available at: https://corrosion.ksc.nasa.gov/Capabilities/AtmosExposure. Accessed on: Nov. 21, 2021.

National Institute for Occupational Safety and Health (NIOSH) (2013) Criteria for a recommended standard: occupational exposure to hexavalent chromium; NIOSH Publication No. 128. Washington, D.C.: NIOSH.

Naval Publication and Form Center (NPFC) (2001) FED-STD-141. Paint, varnish, lacquer and related materials: methods of inspection, sampling, and testing. United States of America: NPFC.

Saillard R, Viguier B, Odemer G, Pugliara A, Fori B, and Blanc C (2018) Influence of the microstructure on the corrosion behavior of 2024-T3 aluminum alloy coated with a trivalent chromium conversion layer. Corros Sci 142:119-132. https://doi. org/10.1016/j.corsci.2018.07.007 